\title{
Ureter Quadruplication with Huge Ureteral Cyst
}

\author{
Joshi $\mathbf{R}^{1}$, Singh DR
}

\begin{abstract}
Ureteral quadruplication is an extremely rare congenital anomaly. It was first reported in 1975. The patients may present with different features and complications in respect to this congenital anomaly. They may also present with other congenital anomalies. Diagnosis sometimes is difficult and may need to be investigated with Magnetic Resonance Urogram, CT scan apart from routine investigations like ultrasonography and intravenous urogram. Surgical treatment should be based on the operative and investigational finding. We present the twelfth reported case but the first from Nepal. It was associated with a large ureteral cyst with diagnostic dilemma. Surgical exploration was done with a provisional diagnosis of large retroperitoneal cyst.
\end{abstract}

Key words: Congenital anomaly, Intravenous Urogram, Quadruplication, Ultrasonography, Ureteral cyst
'Dr. Robin Joshi, Assistant Professor, '2Deepak Raj Singh, Associate Professor. Both from the Department of Urology and Department of Surgery, Kathmandu Medical College and Teaching Hospital, Sinamangal, Kathmandu, Nepal

Address for correspondence:

Dr. Robin Joshi

E-mail: robinjoshi@hotmail.com

\section{How to cite}

Joshi R, Singh DR. Ureter Quadruplication with Huge Ureteral Cyst. J Nepal Paediatr Soc 2015;35(1):79-81.

doi: http://dx.doi.org/10.3126/jnps.v35i1.12229

This work is licensed under a Creative Commons Attribution 3.0 License.

U reter quadruplication is the rarest congenital anomaly among ureter malformations $\mathbf{s}^{1,2,3,4}$. First reported case was by Sodedahl DW et al in $1976^{2}$. Since then 11 such cases have been reported worldwide. Our paediatric case is the first to be reported from Nepal and twelfth in the world. This malformation may be associated with vesico-ureteral reflux (VUR) ${ }^{5}$, dystrophic kidney ${ }^{6}$, or blind ending proximal branches ${ }^{7}$. These patients may also present with contra lateral malformation like contra lateral multicystic dyspastic kidney ${ }^{8}$, triplet ureter, agenesis of the kidney or even bilateral ureteral quadruplication ${ }^{2}$. Recently in 2014 quintoplication of ureter has been reported by Jurkiewicz et al which is first of its kind ${ }^{9}$. The present case is of a girl of 5 years old who presented with distended painful abdomen. After relevant investigations we were unable to come to a definite diagnosis for which surgical exploration was carried out.

\section{The Case}

A five year old girl child presented with abdominal distension and episodic pain in her right side of the abdomen. The intensity of pain had increased for past 20 days. She had no history of urinary or bowel problems in the past. On physical examination, the patient had distended painful abdomen on the right side. She had no fever,

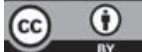

jaundice, or pallor. Haematological and biochemical studies were all within normal limits. Her urine showed plenty pus cells with $75-80 \mathrm{rbc} / \mathrm{hpf}$ and $E$. coli on urine culture. Ultrasonography reported as thick walled retroperitoneal cyst with right mild hydronephrosis and bilateral malrotated kidneys. On Intravenous urogram (IVU), it showed right mild hydronephrosis with bilateral malrotated kidneys (Figure 1).With no obvious conclusion CT-scan was done and revealed thick walled retroperitoneal cyst abutting the right kidney with internal contrast in delayed image and duplex right kidney with obstructed hydronephrotic lower moiety ? Urinoma (Figure 2). She was admitted and intravenous antibiotic 
was started as per her culture and sensitivity of urine culture.

After counselling about the difficulty in diagnosis, patient's parents agreed on surgical exploration and also for possible nephrectomy. On exploration, we found a large retroperitoneal cyst which on further dissection kidney was found attached to it with four branches (Figure 3 ). Not recognizing what they really were, we cut two branches thinking it as adhesion. On due course of dissection, we noticed a long tube distally connected to the cyst. We were unable to understand the anomaly, we requested our one of the resident to web-search immediately. We later concluded this must be a case of quadruplication of ureter with large ureteral cyst and a single ureter (Figure 4). Kidney looked grossly normal as IVU and CT-scan suggested, functioning kidney though DTPA scan was not done. The iatrogenic injury of two upper moiety were anastomosed by Wallace fashion and then to the cyst. The large ureteral cyst underwent reduction pyeloplasty with the single ureter distally as there was a partial stenosis of about $1 \mathrm{~cm}$ at the junction of cyst and ureter. DJ stent of 5 French size was placed to safeguard the anastomosis. The girl was hospitalized for 7 days with removal of drain on the $6^{\text {th }}$ day post-operatively. On follow up after 6 weeks she was free of any post-operative complication and DJ stent was removed. Her parents have been advised to attend the follow up clinic on $3^{\text {rd }}$ and $6^{\text {th }}$ month. She will undergo IVU and possibly DTPA scan on the $6^{\text {th }}$ month.

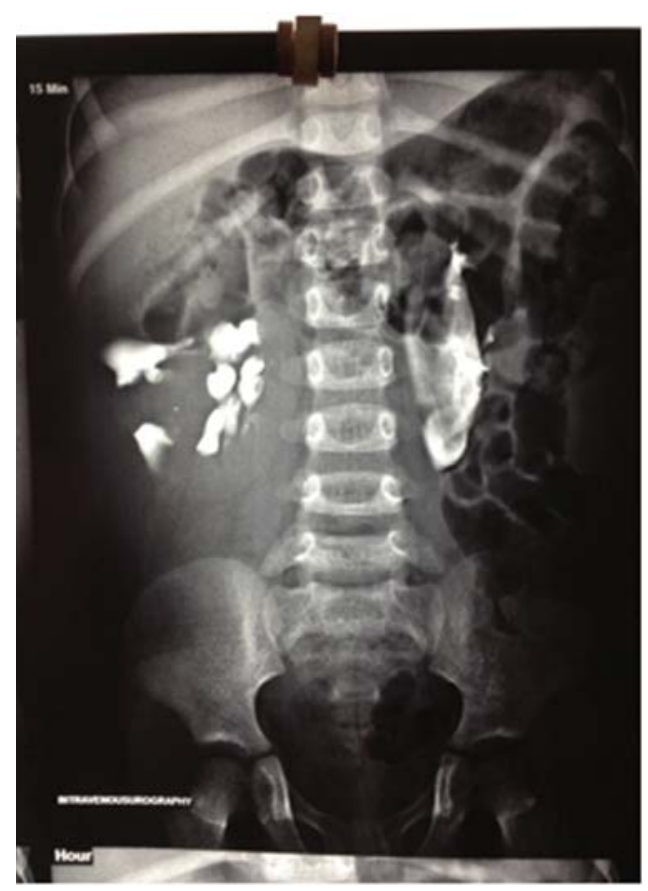

Fig 1: Intravenous urogram showing malposition of Kidneys

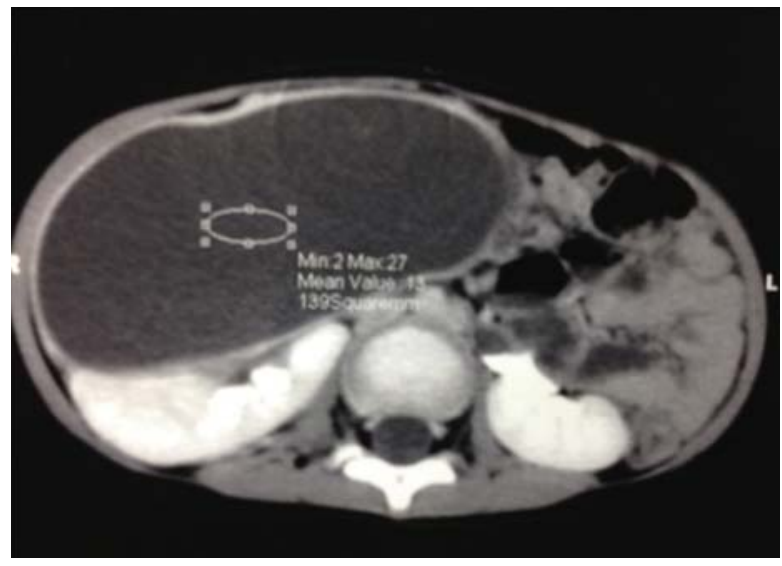

Fig 2: CT scan showing large retroperitoneal cyst with functioning kidney

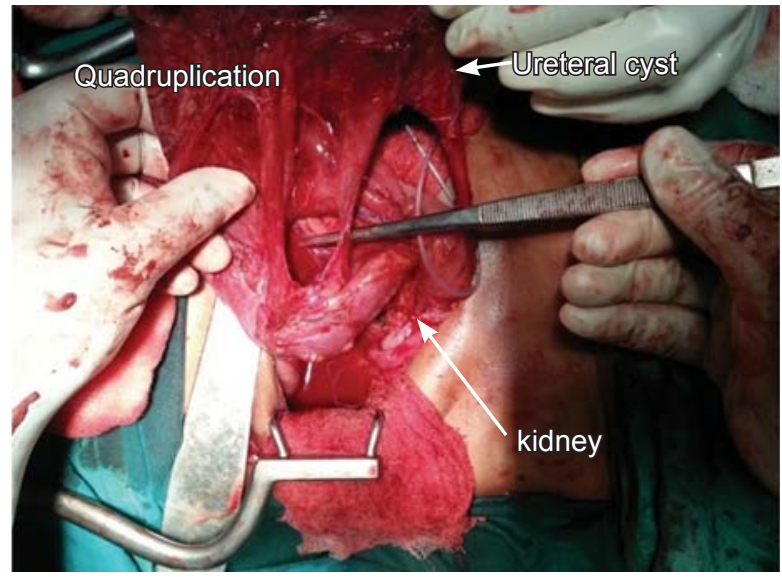

Fig 3: Showing quadruplication of ureter, kidney, large ureteral cyst and single ureter

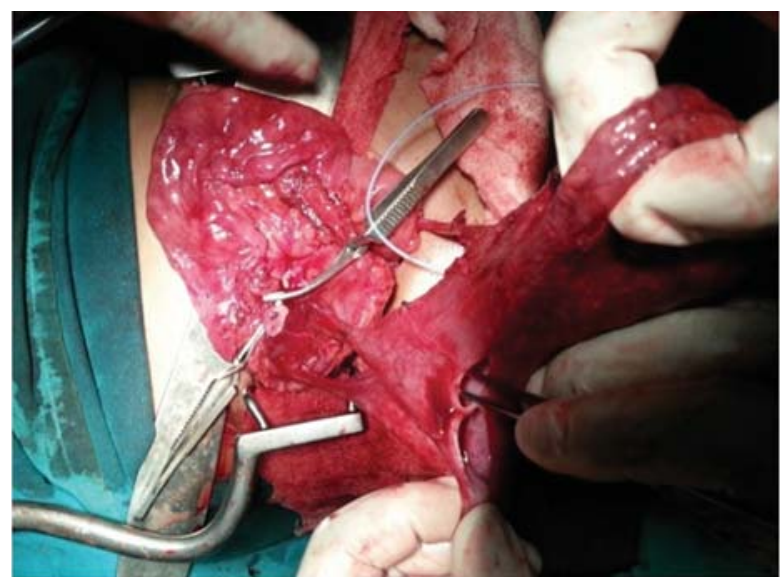

Fig 4: Showing Cut ends of upper moiety, lower moiety, kidney, ureter, ureteral cyst

\section{Discussion}

During the early fourth week of gestation ureteric bud arises as a diverticulum from the Wolffian duct. Once in contact with metanephric mesenchyme it undergoes a dichotomous branching morphogenesis ${ }^{10}$. It has been postulated that AT2 (angiotensin II receptor) 
plays a vital role in directing the site of ureteric bud outgrowth. The defect in this process leads to defective timing and location of outgrowth of ureteric bud leading to congenital ureteral anomalies ${ }^{10}$.

Quadruplication of the ureter is a very rare type of congenital anomaly. The first reported case was by Soderdahl in 1976 and only 11 such cases has been reported worldwide till date ${ }^{2}$. Our case is unique as it presented with huge distended abdomen due huge dilatation of ureteral cyst caused by stenosis of "ureterocysto-pelvic junction" with normal four congenital ureter. Triplication of ureter as described in literature has four varieties according to Smith classification but no such variety is described for the quadruplication of ureter. Quadruplication is associated with many other anomalies like three blind-ending braches, multicystic dysplastic kidney, bilaterality and massive vesicoureteral reflux in the contra-lateral side.

Diagnosis is usually made during surgical exploration as in our case. Preoperative evaluation with IVU, retrograde pyelography may show congenital abnormalities. CT-scan and VCCUG may be needed for further evaluation to look for other ipsi /contralateral anomalies and VUR. DMSA or DTPA scan will indicate the functional status. Magnetic Resonance urography (MRU), if available, may be more diagnostic and may provide high quality images of the urinary tract without using ionizing radiation. MRU can provide both excretory functional and morphological information by using diuretic and contrast media.

There are no general consensus on the surgical procedure .It may differ due to varied presentation of the anomaly. Our case underwent Wallace anastomosis for the iatrogenic injury of the upper two moiety and reduction pyeloplasty for "ureterocystopelvic stenosis". The kidney looked healthy though DTPA scan was not done preoperatively. Massive VUR with impaired renal function can undergo nephreureterectomy ${ }^{5}$. Akaba et $\mathrm{al}^{1}$ preserved the kidney by termino-terminal pyelorenal anastomosis. To preserve the afflicted kidney is justifiable and defendable as in our case but the patient needs to be in regular follow up. Our patient is still under routine regular medical follow up. At sixth month the patient will undergo test like IVU and DTPA to look for postoperative complications like re-stenosis and functional condition.

\section{Conclusion}

Quadruplication of ureter like our case is an extremely rare ureter congenital anomaly. Very few cases are reported worldwide and there is no consensus regarding its treatment options

\section{References}

1. Klinge L, Kubiak R, Slongo T. Quadruplication of the ureter in combination with a large ureteral cyst. Pediatr Surg Int 2001 Sep;17(7):566-8.

2. Soderdahl DW, Shiraki IW, Schamber DT. Bilateral ureteral quadruplication. J Urol 1976, 116:255-6.

3. Jeung HJ, Kwon DD, Oh BR, Ryu SB, Park YI. A case of Unilateral Incomplete Quadruplicated Ureter associated with Ipsilateral Single Ectopic Ureteral Orifice and Renal Dysplasia. Korean J Urol 1998 May; 39(5):507-509.

4. Saxena V1, Kumar R. Bilateral ureteric quadruplication with renal calculus. Urology 2011;77(3):592-3.

5. Vicentini FC1, Denes FT, Srougi M. Ureteral quadruplication associated with ureteral cyst and massive vesicoureteral reflux treated by laparoscopic nephroureterectomy. J Endourol 2007;21(7):769-71.

6. Koszutski T, Kudela G, Mikosiński M, Utrata W. Quadruplication of dystopic kidney in combination with ureteral cyst.' J Pediatr Surg 2008;43(12):e135 .

7. Metin A, Gürel S, Önol ŞY, Önol FF, Gücük A, Boran Ç, Dağıstan E. Ureteral quadruplication with three blind-ending branches. Int Urol Nephrol 2013;45(1):69-71.

8. Moses KA, Scherz HC. Partial ureteral quadruplication with contralateral multicystic dysplastic kidney. Urology 2010;76(2):461-2.

9. Jurkiewicz B, Ząbkowski T, Shevchuk D. Ureteral quintuplication with renal atrophy in an infant after the 1986 Chernobyl nuclear disaster. Urology 2014;83(1):211-3.

10. John M. Park. Normal development of the genitourinary tract. In: Alan J. Wein, editor. Campbell-Walsh Urology . Philadelphia: Elsevier Saunders; 2012 .p. 2975-2985. 